\title{
Farklı Bağlantı Şekillerinin Panel Radyatörlerin Verimleri Üzerine Etkisinin İncelenmesi
}

\author{
Gökhan ÖMEROĞLU* \\ Makine Mühendisliği Bölümü, Mühendislik Fakültesi, Atatürk Üniversitesi, Erzurum, Türkiye \\ gomeroglu@atauni.edu.tr
}

(Geliș/Received: 21/05/2019;

Kabul/Accepted: 29/08/2019)

\begin{abstract}
Öz: Bina 1sıtma sistemlerinin, gerek konfor standartlarının oluşturulması gerekse insanoğlunun sağlıklı yaşam ortamlarında yaşayabilmeleri için uygulanması günümüzde kaçınılmazdır. Bir binanın ısıtma ihtiyacı yaygın olarak fosil yakıtlar kullanılarak 1sıtılan suyun mahal içerisine yerleştirilen radyatörlerde dolaştırılması ile çözümlenmektedir. Mühendisler 1sıtılacak mahaller için radyatör boyutlarını ve boru çaplarını projelendirirken radyatörlere yapılacak bağlantı şekilleri üzerine bir belirleme yapmamaktadırlar. Bu durumda sistemi oluşturan kişilerin tercihleri veya tecrübeleri ile rastgele bağlantılar uygulanmaktadır. Enerjinin etkin ve verimli kullanılması açısından doğru projelendirme ve verimin artırılması günümüz dünyasında oldukça önemlidir. Bu nedenle bir mahal içerisine yerleștirilen bir radyatörün doğru olarak boyutlandırılması veya radyatöre doğru boru çapı ile suyun taşınması kadar suyun giriş ve çıkış yönünün de etkisi önemlidir. Bu çalışmada farklı boylarda modellenen panel radyatörler için 3 farklı bağlantı şeklinin etkisi hesaplamalı akışkanlar dinamiği (CFD) metodu kullanılarak incelenmiștir. Çalışmada radyatör boyunun artması ile panel veriminin bağlantı şekillerine göre azaldığı ve bağlantı şekillerinin verim üzerindeki etkisi gösterilmiștir.
\end{abstract}

Anahtar kelimeler: Panel radyatör, bağlantı şekilleri, verim, cfd analizi.

\section{Investigation of the Effect of Different Connection Types on the Efficiency of Panel Radiators}

Abstract: It is inevitable that building heating systems are used to create comfort standards and to live in healthy living environments of human beings. The heating requirement of a building is widely solved by circulating water heated by using fossil fuels in radiators placed in the space. Engineers do not make a determination on the connection types to be made to the radiators while projecting the radiator dimensions and pipe diameters for the spaces to be heated. In this case, random connections are applied with the preferences or experiences of the people who make up the system. In terms of efficient use of energy, increasing the right design and efficiency is very important in today's world. For this reason, the correct size of a radiator placed in a space or the diameter of the pipe towards the radiator as well as the transportation of water is also important. In this study, the effect of 3 different connection shapes for panel radiators modeled in different lengths were investigated by using computational fluid dynamics (CFD) method. In this study, it was shown that the efficiency of the panel decreases with the increase in radiator length and the effect of the connection shapes on the efficiency.

Key words: Panel Radiator, connection types, efficiency, cfd analysis.

\section{Giriş}

Bir sıcak su 1sıtma sisteminin tasarımında, geleneksel olarak 1sitılacak mahaller için 1sı kaybı hesabı yapılarak panel verimlerine göre radyatör seçimi yapılmaktadır. Dağıtım ve toplama kolon çapları boyutlandırılmakta ve kritik devredeki basınç düşümü, ssı yüklerine göre ve kabul edilen hız sınırları içerisinde hesaplanmaktadır. Son olarak, hesaplanan basınç düşümü de dikkate alınarak kritik devreye su basabilecek şekilde sirkülasyon pompası seçimi yapılmaktadır.

Panel radyatörler günümüzde gerek şık bir görünüme sahip olmaları gerekse yüksek verimleri açısından mahallerin 1sıtılmasında sıkça tercih edilmektedirler. Panel radyatörler her bir tarafina istenildiğinde bağlantı yapılabilecek şekilde üretilmektedirler. Bu sayede ortamlara istenilen şekilde kolayca montaj edilebilmektedirler. Panel radyatörler genellikle ekonomik olması açısından saç (demir) malzemeden üretildikleri gibi yüksek verime sahip ancak daha pahalı alüminyum malzemeler kullanılarak da üretilmektedirler. Radyatörlerin tipleri belirlenirken etken parametre kanat sayısıdır. Birbirlerinden farklı 1sıtma gücüne sahip radyatör tipleri genel olarak, P, PK, PKP, PKKP, PKKPKP olarak üretilmektedir. P (panel) ve K(kanat) sayısına bağlı olarak üretilen radyatörlerden yaygın olarak kullanılan tip PKKP'dir. [1]

Panel radyatörlerde dolaşan su iki farklı 1sı transfer mekanizması ile mahale iletilmektedir. Radyatörde dolaşan su panel yüzeyinde hareket ettiğinden ısı radyasyon (ışınım) yolu ile öncelikle ortama aktarılmaktadır.

\footnotetext{
* Sorumlu yazar: gomeroglu@atauni.edu.tr. Yazarın ORCID Numarası: 0000-0001-7237-2311
} 
Ayrıca taşınım ile de ortam içerisinde havanın 1sıtılması da sıcak suyun ortama 1sı transferi açısından bir başka yoldur. Ancak bu durumda taşınımın ve ışınımın daha efektif olarak gerçekleştirilmesi için radyatörlerin önüne veya üzerine ister dekoratif amaçlı olsun isterse yerleştirme açısından olsun eşyaların doğru bir şekilde yerleştirilmesi, radyatörlerin ön ve üst yüzeylerinin kapatılmaması gerekmektedir. [1]

Radyatörlerin mahallerde kullanılmasında etrafındaki engellerin ssıtma verimliliği açısından önemi üzerine yapılan çalışmada, \%20'ye kadar ısıl verimin değiştiği ve eşyaların radyatörlere yerleştirilme mesafesi açısından en ideal durumun ise eşya yerleşiminin 1,85 metreden daha büyük mesafeler için her iki tarafı açık radyatörler olduğu tespit edilmiştir. [2]

Panel radyatörlerin doğru bir şekilde montajı ve kullanım şartları açısından yapılan çalışmada; radyatörlerin üzerinin kimyasal sıvılarla değil nemli bir bezle silinmesi, temizliğinin yılda en az bir defa yapılması, sistem içerisinde sıkışan havanın boşaltılması, verimli kullanılmaları açısından termostatik vana uygulanması ve radyatörlerin korozyona uğramaması için sıkça içerdiği suyun boşaltılmaması gerektiği vurgulanmıştır. [3]

Panel radyatörlerin mahallerde kullanımında verimliliğini düşüren başka bir etken ise radyatörün dış duvara kalan tarafından ısı kaybının gerçekleşmesidir. Radyatörün dış duvara bakan kısmı poliüretan yalıtım malzemesi ile kaplandığında yalıtımsız haline göre daha verimli hale geldiği gözlemlenmiştir. [4]

Tip-22-600x500 çelik panel radyatör modeli kullanılarak yapılan çalışmada panel radyatörün farklı bağlantı şekillerine göre termal verimi CFD analizi ile incelenmiştir. Ayrıca 1sı taşınım katsayısında meydana gelen değişimin 1 sıl güç üzerindeki etkisi de araştırılmıştır. "Üstten girişi, çapraz tarafta alttan çılkışı olan bağlantı için, kütle debisi dağıllmı ilk iki ve son ü̧ dikey kanalda olması gereken akıştan daha fazla olduğu belirlenmiştir. Üstten girişi, aynı tarafta alttan çıkışı olan bağlantı için, kütle debisi dağıllmı ilk dört dikey kanalda olması gereken akıştan daha fazla olduğu belirlenmistir. Geri kalan dikey kanallarda, kütle debisi dağıllmının nerdeyse sıfira eşit olduğu görülmektedir. Üstten girişi, çapraz tarafta alttan çıkışı olan bağlantı ve üstten girişi, aynı tarafta alttan çıklşı olan bağlantı için sayısal sonuçlar ve ticari katalog değerleri birbirine çok yakındır ve bu yüzden iki ana bağlantı yöntemi de bu panel radyatör için kullanılabileceği gösterilmiştir.” [5]

Paneller arasına yerleştirilen bir veya iki yüksek emisyonlu levha kullanılarak yapılan çalışmada radyatörlerin $1 s ı l$ verimlerinin klasik tiplere göre arttı̆̆ gözlemlenmiş ayrıca kullanılan bu levhaların 1sı geçişini azaltan tozlanmaya karşı daha dirençli olduğu görülmüştür. [6]

$\mathrm{Bu}$ çalı̧̧mada ise bireysel veya merkezi isıtma sistemlerinde en sık tercih edilen, genel olarak kullanılan mimari tiplerinde uygulama veya mahal büyüklükleri açısından yaygın olarak kullanılan; PKKP tipinde $600 \mathrm{~mm}$ yüksekliğinde ve 1-2-3m uzunluklarında olan panel radyatörler için 3 farklı bağlantı şekillerinin ısıl verim üzerine etkisi hesaplamalı akışkanlar dinamiği (CFD) yöntemi ile incelenmiştir. Panel radyatörün boyu arttıkça bağlantı şeklinin öneminin arttığı belirlenmiştir.

\section{Materyal ve Yöntem}

Bu çalışmada Solidworks Flow Simulation [7] programı kullanılarak 2 boyutlu CFD analizi yapılmıştır. Genel olarak sıkça tercih edilen 1sıtma parametreleri olan 70/55 su giriş/su çıkış derecelerinde, yerçekimi etkisi aktif edilerek $0,045 \mathrm{~kg} / \mathrm{s}$ debi değerinde, hexahedral mesh yapısında minumum boşluk oranı $0,006 \mathrm{~m}$ ve kararlı hal çözümlemesi olacak şekilde analizler yapılmıştır. Ele alınan problem 2 boyutlu, akışkan laminar ve türbülanslı, ortam sıcaklığ $120^{\circ} \mathrm{C}$ alınarak analizler yapılmıştır. Radyatör boyutları 600/1000-2000 ve 3000 olarak alınmıştır.

Panel radyatörler için ekonomik ısıtma sağlamak için kombinin belli sıcaklık aralıklarında çalıştırılması tek başına yeterli değildir. Tesisat borularının radyatörlere bağlanış şeklinin önemli olduğu bilinmekte ancak bunun tesisatın yapısı ve radyatörün uzunluğu ile değişebileceği göz ardı edilmektedir. Yani, herhangi bir bağlantı şekli tüm radyatör boyları için en uygun tercih olmayabilmektedir. Çünkü tesisat boru çapları, radyatör kapasiteleri veya sirkülasyon pompası gücü gibi parametrelerin sistemde dolaşan suyun radyatörler içerisinde her noktaya ulaşabilmesini doğrudan etkilediği bilinmektedir [8] . Şekil 1'de modellenen radyatörler, Şekil 2'de ise olası panel bağlantıları şematik olarak gösterilmiştir. Mantıken panelin her noktasına suyun rahatlıkla dağılabilmesi için panelin her iki tarafından bağlantı yapılması doğru bir tercih gibi gözükmektedir. Ancak her bağlantı şeklinin radyatörün performans verimi üzerine etkisinin ayrı ayrı değerlendirilmesi gerekmektedir. 

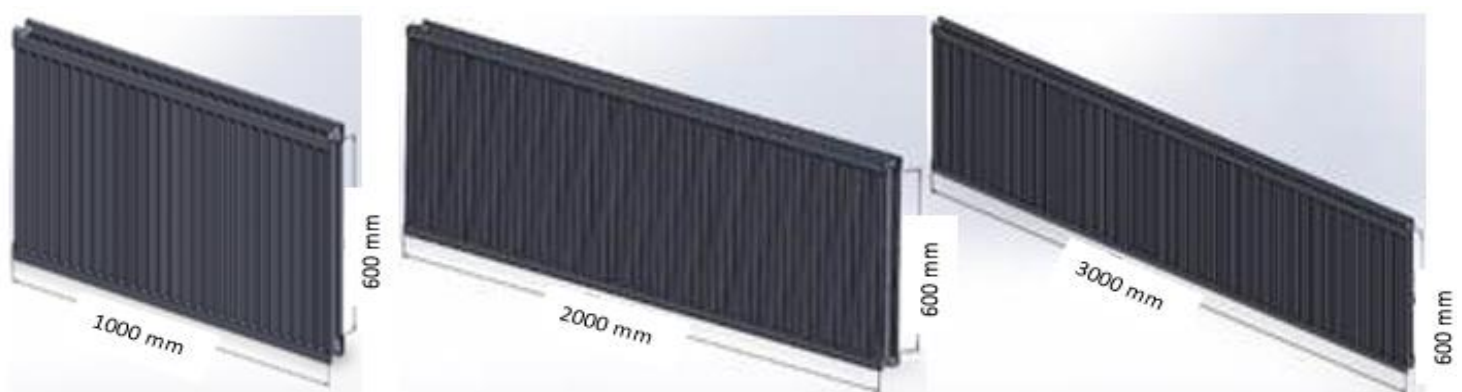

Şekil 1. Modellenen 1, 2 ve 3 metre panel radyatörler

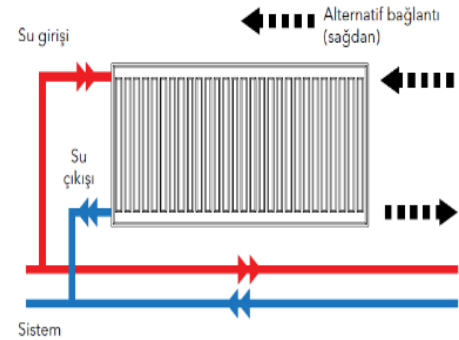

(Tip 1)

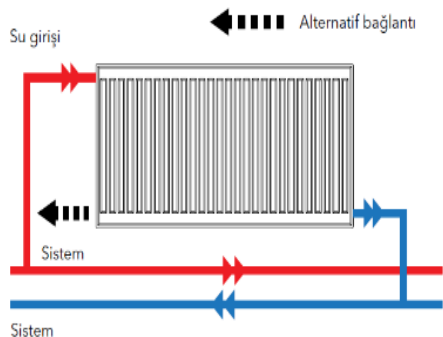

(Tip 2)

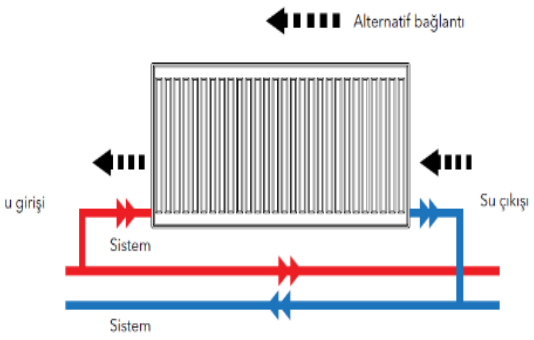

(Tip 3)

Şekil 2. Radyatör bağlantı tipleri: tip 1: paralel, tip 2: çapraz ve tip 3: alt giriş-çıkış .[8]

Analizleri yapılacak panel radyatörlerin üzerindeki sıcaklık değerlerinin ortalaması ve içerdikleri su miktarlarına göre ısıl hesaplamaları için (1) kullanılmıştır;

$\mathrm{Q}=\mathrm{m} \cdot \mathrm{c} \cdot \Delta \mathrm{t}$

Burada, m sıvı kütlesi olup yapılan modelin $1 \mathrm{~m}$ boyutu için yaklaşık 7,5 litre su barındıracak şekilde modellenmiş ve suyun özgül ısı değeri ortalama $4186 \mathrm{~J} / \mathrm{kg}^{\circ} \mathrm{C}$ olarak alınmıştır.

Tablo1. Farklı tip ve boyutlarda ki panel radyatörlerin ısıl verimleri. [9]

\begin{tabular}{|c|c|c|c|c|c|c|c|c|c|}
\hline \multicolumn{10}{|c|}{ ISIL VERIM TABLOSU (Watt) } \\
\hline \multicolumn{2}{|l|}{$20^{\circ} \mathrm{C}$} & \multirow{2}{*}{\multicolumn{2}{|c|}{$\begin{array}{l}\text { TYPE } 11 \\
\text { H (mm) }\end{array}$}} & \multirow{2}{*}{\multicolumn{2}{|c|}{$\begin{array}{l}\text { TYPE } 21 \\
\text { H (mm) }\end{array}$}} & \multirow{2}{*}{\multicolumn{2}{|c|}{$\begin{array}{l}\text { TYPE22 } \\
\text { H (mm) }\end{array}$}} & \multirow{2}{*}{\multicolumn{2}{|c|}{$\begin{array}{l}\text { TYPE } 33 \\
\text { H (mm) }\end{array}$}} \\
\hline \multirow{2}{*}{$L(\mathrm{~mm})$} & \multirow{2}{*}{$\frac{\mathrm{t} 1 / \mathrm{t} 2}{\left({ }^{\circ} \mathrm{C}\right)}$} & & & & & & & & \\
\hline & & 500 & 600 & 500 & 500 & 500 & 600 & 500 & 600 \\
\hline \multirow{4}{*}{1000} & $90 / 70$ & 892 & 1070 & 1296 & 1547 & 1808 & 2110 & 2366 & 2829 \\
\hline & $75 / 65$ & 701 & 841 & 1021 & 1217 & 1446 & 1688 & 1856 & 2214 \\
\hline & $70 / 55$ & 611 & 732 & 889 & 1059 & 1157 & 1350 & 1614 & 1921 \\
\hline & $55 / 45$ & 358 & 428 & 523 & 621 & 727 & 848 & 942 & 1113 \\
\hline \multirow{4}{*}{2000} & $90 / 70$ & 1783 & 2141 & 2592 & 3093 & 3615 & 4220 & 4731 & 5658 \\
\hline & $75 / 65$ & 1403 & 1682 & 2041 & 2434 & 2892 & 3376 & 3713 & 4427 \\
\hline & $70 / 55$ & 1221 & 1463 & 1778 & 2119 & 2314 & 2701 & 3228 & 3842 \\
\hline & $55 / 45$ & 717 & 856 & 1046 & 1243 & 1453 & 1696 & 1883 & 2226 \\
\hline \multirow{4}{*}{3000} & $90 / 70$ & 2675 & 3211 & 3888 & 4640 & 5423 & 6330 & 7097 & 8487 \\
\hline & $75 / 65$ & 2104 & 2523 & 3062 & 3,650 & 4338 & 5064 & 5569 & 6641 \\
\hline & $70 / 55$ & 1832 & 2195 & 2667 & 3178 & 3470 & 4051 & 4842 & 5763 \\
\hline & $55 / 45$ & 1075 & 1284 & 1568 & 1864 & 2180 & 2545 & 2825 & 3340 \\
\hline
\end{tabular}


Yapılacak hesaplamalarda her bir radyatörün ortalama yüzey sıcaklı̆̆ı ile ihtiva ettiği su hacmine göre sahip olduğu isıl kapasitesi tablo-1'de verilen verilerden TYPE-22, H=600 mm ve $L=1000,2000$ ve $3000 \mathrm{~mm}$ değerlerinde ki 1 sıl verimlere göre karşılaştırılarak her bir radyatör ve bağlantı şeklinin ortalama verimleri bulunmuştur. Daha sonra en iyi bağlantı şekli ve en kısa radyatör için bulunan verim değeri \%100 alınarak diğer boylara ve bağlantı şekillerine göre verim farkları kıyaslanmıştır.

\section{Değerlendirme ve Tartışma}

Şekil-3’te $1 \mathrm{~m}$ uzunluğunda ki radyatörlerin 3 farklı bağlantı şekline göre sıcaklık dağılımları verilmiştir. Görüleceği üzere tip-1 ve tip-2 bağlantı şekillerinde ki sıcaklık dağılımları benzer çıkmış tip-3 te ise sıcaklık daha farklı bir dağılıma uğramıştır. Bölgesel olarak tip-1 ve tip-2 de suyun giriş tarafı ve çıkış tarafına doğru sıcaklıklar artarken çıkıș bölgesinin zıt tarafında $25^{\circ} \mathrm{C}$ 'ye kadar sıcaklık düşüşleri gözlemlenmiștir. Tip-3 bağlantı şeklinde ise su alt bölgeden girip alt bölgeden çıktığ için radyatörün sıcaklı̆̆g daha homojen olarak dağılmasına rağmen radyatörün orta ve üst kısmi bölgelerde $35^{\circ} \mathrm{C}$ 'ye kadar sıcaklık düşüşleri olmuştur.
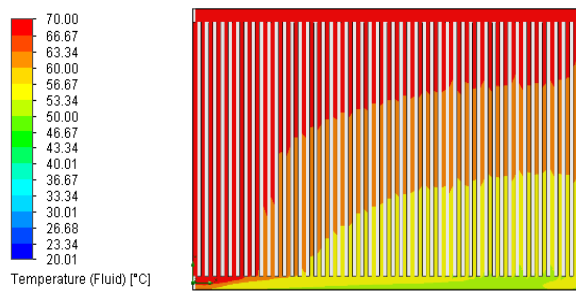

(Tip 1)

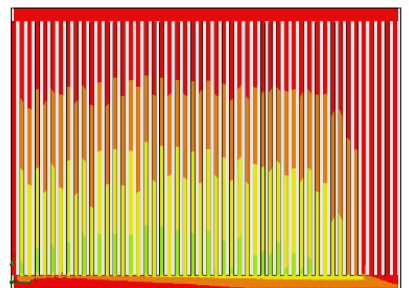

(Tip 2)

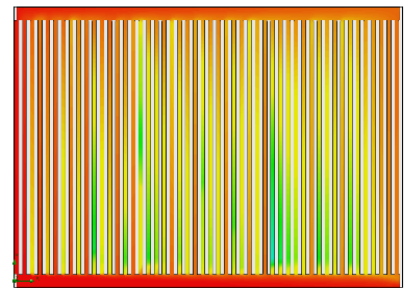

(Tip 3)

Şekil 3. $1 \mathrm{~m}$ uzunluğunda radyatörler için 70/55 giriş-çıkış değerlerine göre sıcaklık dağılımları

Tablo-2 de sıcaklık dağılımlarının minimum, maksimum ve ortalama değerleri verilmektedir. Tablodan görüleceği üzere 3 tip bağlantı şekli için ortalama yüzey sıcaklıkları sırasıyla tip-1> tip-2>tip-3'tür.

Tablo 2. $1 \mathrm{~m}$ uzunluğunda ki radyatör için farklı bağlantı tiplerine göre sıcaklık değerleri

\begin{tabular}{|l|c|c|c|}
\hline Parametre & Tip-1 & Tip-2 & Tip-3 \\
\hline Akışkanın minumun sıcaklığ $1\left[{ }^{\circ} \mathrm{C}\right]$ & 47,73 & 45,91 & 35,79 \\
\hline Akışkanın maksimum sıcaklığ $\left[{ }^{\circ} \mathrm{C}\right]$ & 70,00 & 70,00 & 70,00 \\
\hline Akışkanın ortalama sıcaklığı $\left[{ }^{\circ} \mathrm{C}\right]$ & 63,06 & 62,60 & 60,29 \\
\hline Akışkanın hacmi $\left(\mathrm{m}^{3}\right)$ & 0,007 & 0,007 & 0,007 \\
\hline
\end{tabular}

Şekil-4'te $2 \mathrm{~m}$ uzunluğunda ki radyatörlerin 3 farklı bağlantı şekline göre sıcaklık dağılımları verilmiştir. Görüleceği üzere tip-1 bağlantı şeklinde radyatörün sağ alt bölgesi ile sol üst bölgesi arasında farklı sıcaklık dağılımları oluşmuştur. $37^{\circ} \mathrm{C}$ 'ye kadar bölgeler arası sıcaklık farkları meydana gelmiştir. Tip-2 bağlantı şeklinde sıcaklık dağılımı radyatörün geneline tip-1'e göre daha iyi yayılmasına karşın ortalama sıcaklık düşüşleri daha çok radyatörün alt-orta kısmında $35^{\circ} \mathrm{C}$ 'ye kadar düştüğü gözlemlenmiştir. Tip-3 bağlantı şeklinde ise yine sıcaklık dağılımı tip-1 bağlantı şekline göre daha homojen olmasına karşın radyatörün orta-sağ bölgesinde sıcaklık değerlerinin $31^{\circ} \mathrm{C}$ ye kadar düştüğü gözlemlenmiştir.

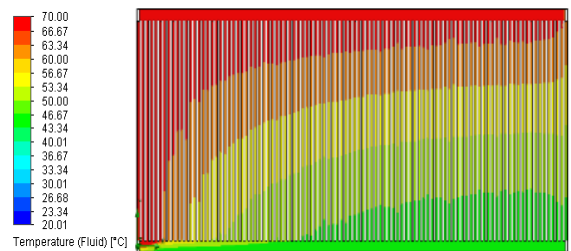

(Tip 1)

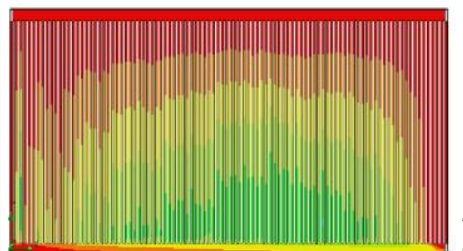

(Tip 2)

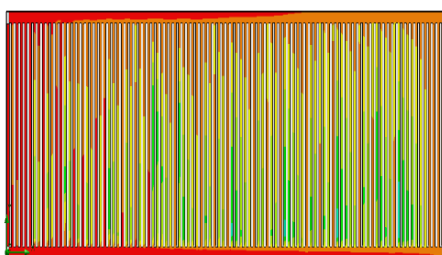

(Tip 3)

Şekil 4. 2 m uzunluğunda radyatörler için 70/55 giriş-çıkış değerlerine göre sıcaklık dağılımları 
Tablo-3 de sıcaklık dağılımlarının minimum, maksimum ve ortalama değerleri verilmektedir. Tablodan görüleceği üzere 3 tip bağlantı şekli için ortalama yüzey sıcaklıkları sırasıyla tip-2> tip-3>tip-1'dir.

Tablo 3. $2 \mathrm{~m}$ uzunluğunda ki radyatör için farklı bağlantı tiplerine göre sıcaklık değerleri

\begin{tabular}{|l|c|c|c|}
\hline Parametre & Tip-1 & Tip-2 & Tip-3 \\
\hline Akışkanın minumun sıcaklığ1 $\left[{ }^{\circ} \mathrm{C}\right]$ & 33,48 & 35,13 & 39,10 \\
\hline Akışkanın maksimum sıcaklığ $\left[{ }^{\circ} \mathrm{C}\right]$ & 70,00 & 70,00 & 70,01 \\
\hline Akışkanın ortalama sıaklığ $\left[{ }^{\circ} \mathrm{C}\right]$ & 57,70 & 59,00 & 58,54 \\
\hline Akışkanın hacmi $\left(\mathrm{m}^{3}\right)$ & 0,015 & 0,015 & 0,015 \\
\hline
\end{tabular}

Şekil-5’te 3m uzunluğunda ki radyatörlerin 3 farklı bağlantı şekline göre sıcaklık dağılımları verilmiştir. Görüleceği üzere tip-1 bağlantı şeklinde neredeyse radyatörün sadece üst ve giriş bölgesinde sicaklığın sadece

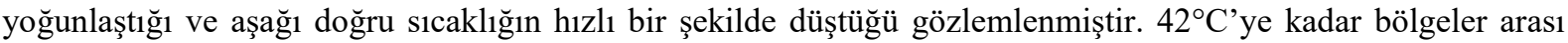
sıcaklık farkları meydana gelmiştir. Tip-2 bağlantı şeklinde sıcaklık dağılımı radyatörün geneline tip-1'e göre daha iyi yayılmasına karşın sıcaklık düşüşleri daha çok radyatörün alt-orta bölgesinin çok düşük bir kısmında ortam sicaklığı olan $20^{\circ} \mathrm{C}$ ye kadar düştüğü gözlemlenmiştir. Tip-3 bağlantı şeklinde ise yine sıcaklık dağılımı tip-1 bağlantı şekline göre daha homojen olmasına karşın radyatörün alt-sağ bölgesinin bazı kısımlarında sıcaklık değerlerinin ortam sıcaklığına kadar düştüğü yani o belirtilen bölgelerde suyun neredeyse hiç dolaşım yapmadığ gözlemlenmiştir.

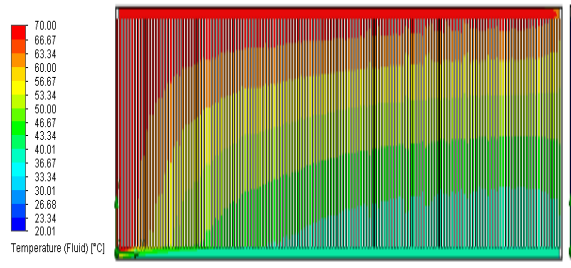

(Tip 1)

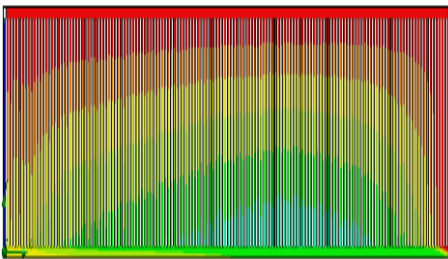

(Tip 2)

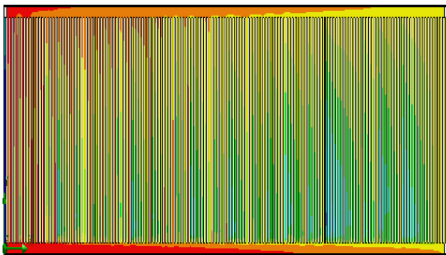

(Tip 3)

Şekil 5. 3 m uzunluğunda radyatörler için 70/55 giriş-çıkış değerlerine göre sıcaklık dağılımları

Tablo-4 de sıcaklık dağılımlarının minimum, maksimum ve ortalama değerleri verilmektedir. Tablodan görüleceği üzere 3 tip bağlantı şekli için ortalama yüzey sıcaklıkları sırasıyla tip-2> tip-3>tip-1'dir.

Tablo 4. $3 \mathrm{~m}$ uzunluğunda ki radyatör için farklı bağlantı tiplerine göre sıcaklık değerleri

\begin{tabular}{|l|c|c|c|}
\hline Parametre & Tip-1 & Tip-2 & Tip-3 \\
\hline Akışkanın minumun sıcaklığ1 $\left[{ }^{\circ} \mathrm{C}\right]$ & 28,73 & 20,14 & 20,19 \\
\hline Akışkanın maksimum sıcaklığ $1\left[{ }^{\circ} \mathrm{C}\right]$ & 70,00 & 70,00 & 70,00 \\
\hline Akışkanın ortalama sıcaklığ $1\left[{ }^{\circ} \mathrm{C}\right]$ & 53,75 & 55,75 & 54,02 \\
\hline Akışkanın hacmi $\left(\mathrm{m}^{3}\right)$ & 0,022 & 0,022 & 0,022 \\
\hline
\end{tabular}

Şekil-6'da radyatör boyuna ve bağlantı şekillerine göre ortalama yüzey sıcaklığı en fazla olan radyatör boyu ve bağlantı şekli referans alınarak yapılan grafik verilmiştir. Grafik incelendiğinde panel radyatörler içerisinde sıcaklık dağılımının uzunluk arttıkça azaldığı (verimin azaldığı) ve bağlantı şekillerinin öneminin radyatör uzunluğu arttıkça daha belirgin olarak değiştiği görülmektedir. Grafik oluşturulurken en iyi performansa sahip radyatörün verimi \%100 kabul edilip diğer uzunluk ve bağlantı şekilleri ile kıyaslanması yapılmıştır. Şekil de en iyi performansa sahip radyatörün $1 \mathrm{~m}$ uzunluğunda üst-alt bağlantıya sahip radyatör olduğu görülürken, ek kötü performans $3 \mathrm{~m}$ uzunluğunda yine üst-alt bağlantıya sahip radyatörde olduğu görülecektir. Bu durum, radyatör uzunluğunun $1 \mathrm{~m}$ den daha fazla artması durumunda üst-alt( tip-1) bağlantı şeklinin diğer bağlantı şekillerine göre uygun bir bağlantı şekli olmadığının sonucunu doğurmaktadır. Uzunluk artması sonucu en performanslı bağlantı türü çapraz (tip-2) olandır. 


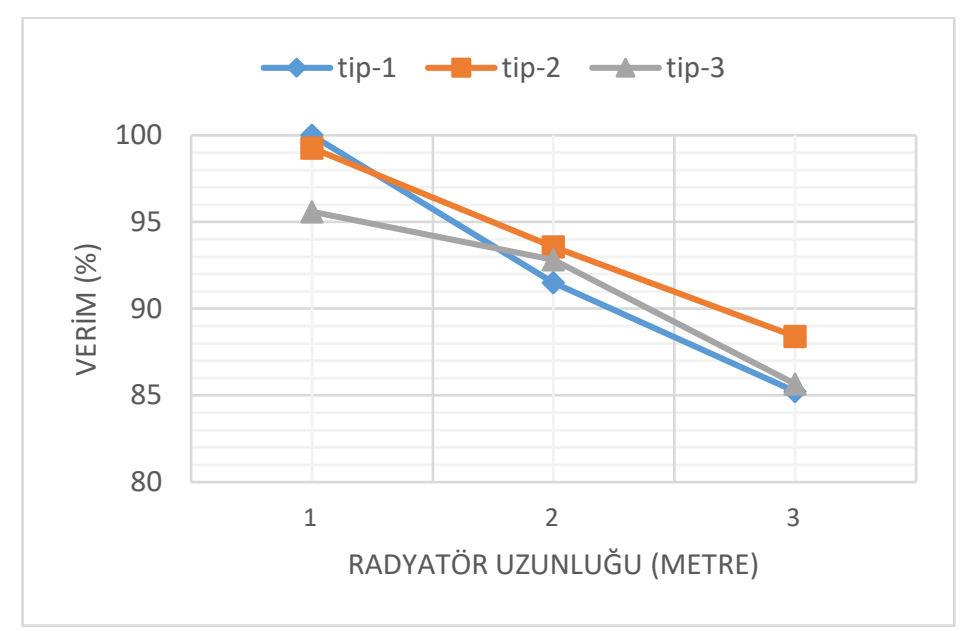

Şekil 6. Bağlantı şekillerinin farklı boyutlarda ki radyatörlerin verimleri üzerindeki etkisi

\section{Sonuçlar}

Bu çalışmada, $20^{\circ} \mathrm{C}$ ortam sıcaklı̆̆ındaki bir mahalde, $70 / 55$ gidiş-dönüş sıcaklığında, 3 farklı bağlantı şekli ve 3 farklı boydaki panel radyatörler için sıcaklık dağılımları Solidworks Flow Simulation programı kullanılarak incelenmiştir. Elde edilen sıcaklık değerlerinin dağılımları ve ortalama sıcaklık değerleri incelendiğinde;

- Mahaller için cihaz seçimi yapılırken radyatör boyu arttıkça verimin düştüğü, radyatörün yüzeyinde daha çok ısınmayan bölgeler oluştuğu gözlemlenmiştir. Bu bakımdan bir mahale radyatörler yerleştirilirken mümkün olduğunca tek parça uzun tip kullanmak yerine 1sı yükünün bölünerek birkaç adet radyatör yerleștirilmesinin daha uygun olduğu görülmüştür.

- Panel radyatörlerde giriş-çıkış bağlantı şekillerinin önemi uzunluğa göre artmaktadır.

- $1 \mathrm{~m}$ uzunluğunda ki radyatörde bağlantı şeklinin etkisi neredeyse fark etmez iken $3 \mathrm{~m}$ uzunluğunda ki radyatörde ortalama yüzey sıcaklığı $2^{\circ} \mathrm{C}$ kadar değişmektedir. Yani birden çok radyatör bulunan ve tip$2^{\prime}$ 'ye göre bağlantısı yapılan mahallerin aynı çalışma ve ortam koşullarında tip-1 ve tip-3 e göre daha verimli isıtılacağı aşikârdır.

Radyatör bağlantı şekillerinden tip-2 (çapraz) bağlantı şeklinin özellikle radyatör boyu arttıkça diğer bağlantı şekillerine göre daha verimli olduğu sonucuna varılmıştır.

\section{Kaynaklar}

[1] http://www.iyiradyator.com/index.asp?Sayfa=Radyator,Nedir

[2] Kibar A, VEZİROĞLU A.R. Mekân İçerisindeki Radyatörlerin Etrafındaki Engellere Göre Isıl Veriminin İncelenmesi. Tesisat Mühendisliği;136: Temmuz/Ağustos 2013.

[3] DAŞDEMIR A. Panel Tip Radyatörlerin Montajı ve Kullanımında Dikkat Edilmesi Gereken Hususlar. Tesisat Mühendisliği; 146: Mart/Nisan 2015.

[4] YILMAZ E. Exterior surface insulated panel radiator and energy efficiency analysis. International Advanced Researches and Engineering Journal; 01: December,2017.

[5] AYDAR E, EKMEKÇİ İ. Thermal Efficiency Estimation Of The Panel Type Radiators With Cfd Analysis. Isı Bilimi ve Tekniği Dergisi; 32, 2: 63-71, 2012.

[6] Beck S, M. B., Grinsted S.C, Blakey S.G, et al. A novel design for panel radiators. Applied Thermal Engineering; 24 : 1291-1300, 2004.

[7] https://www.solidworks.com/tr/product/solidworks-flow-simulation

[8] Kalorifer Tesisatı Proje Hazırlama Esasları Kitabı. TMMOB, Makina Mühendisleri Odası, 259-100.

[9] Kalde Radyatör Kataloğu. 2014 TR. 